Süt dişlerinde demir ilacına bağlı renklenmeler üzerine yüzey örtücü kullanımının etkisi

\section{The effect of surface sealants on discoloration of primary teeth related to iron syrups}

\author{
Dr. Öğr.Üyesi Emine Kaya \\ İstanbul Okan Üniversitesi, Diş Hekimliği Fakültesi, \\ Pedodonti A.D., İstanbul \\ Orcid ID: 0000-0002-9347-148X
}

Geliş tarihi: 4 Kasım 2020

Kabul tarihi: 12 Ocak 2021

doi: 10.5505/yeditepe.2021.64426

\section{Yazışma adresi:}

Dr. Öğr. Üyesi Emine Kaya

İstanbul Okan Üniversitesi, Diş Hekimliği Fakültesi,

Pedodonti A.D. Aydıntepe Mah. Necmettin Erbakan

Cad. No:2 Tuzla.

Tel: +905533583870

E-posta:eminetass@gmail.com

\section{ÖZET}

Amaç: Bu çalışmanın amacı, süt dişlerine uygulanan yüzey örtücü ajanların, çocuklarda kullanılan iki farklı formdaki demir şurubunun meydana getirdiği renklenme üzerindeki etkisinin incelenmesidir.

Gereç ve Yöntem: Çalışmada toplam 66 adet çürüksüz süt dişi, her bir grupta 11 adet örnek bulunacak şekilde rastgele 6 gruba ayrıldı. $\mathrm{Fe}^{+2}$ (ferröz sülfat) içeren Ferrum Haussman (Vifor International Inc., İsviçre) ve $\mathrm{Fe}^{+3}$ (ferrik polimaltoz) içeren FerroSanol B (UCB Pharma GmbH, Almanya) demir şurubu kullanıldı. Kontrol grubu olarak distile su tercih edildi. Her bir şurup ve kontrol grubundaki örneklerin yarısına yüzey örtücü ajan olarak BisCover LV (Bisco Inc., Itasca, IL, ABD) uygulandı ve diğer yarısına herhangi bir işlem yapılmadı. Her bir diş örneği günde 3 kere 8 saat aralıklarla 2'şer dakika bulunduğu gruba göre demir şuruplarına veya distile suya batırıldı. Toplamda 252 daldırma döngüsü uygulandı. Renk değişimleri spektrofotometre (Vita EasyShade Advance 4.0, Ivoclar Vivadent, Liechtenstein) kullanılarak ölçüldü. İki yönlü varyans analizi, renk değişiminin değerlendirilesinde kullanıldı.

Bulgular: $\mathrm{Fe}^{+2}$ içeren demir şurup grubundaki dişler $\mathrm{Fe}^{+3}$ içeren demir şurubu grubundaki dişlerden daha fazla renk değişimi gösterdi. ( $p<0,001)$ Tüm gruplarda yüzey örtücü uygulanan dişlerde uygulanmayan dişlere göre daha fazla renk değişimi görüldü. $(p<0,001)$

Sonuçlar: Bu invitro çalışmada $\mathrm{Fe}^{+2}$ içeren demir şuruplarının $\mathrm{Fe}^{+3}$ içeren şuruplara göre daha fazla renklenmeye neden olduğu görüldü. Yüzey örtücü ajanlar süt dişlerinde demir ilacına bağlı oluşan renklenmeleri önlemekte etkili değildir.

Anahtar kelimeler: Demir renklenmesi, süt dişi, yüzey örtücü

\section{SUMMARY}

Aim: This study aimed to investigate the effect of surface sealant agents applied to primary teeth on discoloration caused by two different forms of iron syrup used in children.

Material and Methods: In this study, a total of 66 intact primary teeth were randomly divided into 6 groups, with 11 samples in each group. Ferrum Haussman (Vifor International Inc., Switzerland) containing $\mathrm{Fe}^{+2}$ (ferrous sulfate) and FerroSanol B (UCB Pharma GmbH, Germany) containing Fe ${ }^{+3}$ (ferric polyimaltose) were used. Distilled water was chosen as a control group. BisCover LV (Bisco Inc., Itasca, IL, USA) was applied to the half of the samples as a surface sealant agent and the other half of the samples was not treated. Each tooth sample based on the group type was immersed in iron syrups or distilled water for 2 minutes at 8 hour intervals, 3 times a day. A total of $252 \mathrm{immersion}$ cycles were applied. Color changes were measured by using a spectrophotometer (Vita EasyShade Advance 4.0, Ivoclar Vivadent, Liechtenstein). Twoway ANOVA was used to evaluate the effects of color change. Results: Samples in the $\mathrm{Fe}^{+2}$ syrup group showed more discoloration than the samples in the $\mathrm{Fe}^{+3}$ syrup group. $(\mathrm{p}<0.001)$ In iron syrups and control group, the samples with surface 
sealent exhibited more discoloration than the rest of the samples. $(p<0.001)$

Conclusions: In this in vitro study, it was observed that iron syrups containing $\mathrm{Fe}^{+2}$ caused more discoloration than the iron syrups containing $\mathrm{Fe}^{+3}$. For primary teeth, surface sealants were inefficient on the protection against discoloration caused by iron syrups.

Keywords: Iron staining, primary teeth, surface sealant

\section{GiRiş}

Demir eksikliği anemisi (DEA), dünya çapında hem gelişmiş hem de gelişmekte olan ülkelerde ortaya çıkan önemli bir sağlık sorunudur. Türkiye genelinde, çocuk polikliniklerine başvuran hastalarda DEA'nin sıklığının \%17-30 arasında olduğu bildirilmiştir.1,2 Tedavinin temel prensipleri arasında; beslenmenin iyileştirilmesi, demir takviyesi ve hastaların bilinçlendirilmesi yer almaktadır. DEA tedavisinde çocuklarda, ağız yoluyla en çok +2 değerlikli demir tuzları, +3 değerlikli demir polimaltoz kompleksleri ve son zamanlarda kullanımı artan kombine +2 değerlikli demir ve çinko preparatları kullanılmaktadır. Damla ve şurup şeklindeki demir takviyeleri uyum kolaylığı ve yan etkilerinin az olması gibi avantajları nedeniyle çocuklarda sıklıkla tercih edilmektedir. ${ }^{3}$ Ancak metalik tat ve dişlerde siyah renklenmeye neden olması gibi önemli dezavantajları da bulunmaktadır. Dişlerde görülen siyah renklenme genellikle ebeveynler için endişe vericidir ve bu tür renklenmelerin okul öncesi çocukların sosyal etkileşimlerini olumsuz yönde etkileyebileceği düşünülmektedir. ${ }^{4}$

Dişlerde görülen siyah renklenmelerin, demir iyonları ve dişeti sıvısı arasındaki karşılıklı etkinin oluşturduğu çözünmez ferrik sülfit bileşiğinden veya bakterilerin neden olduğu hidrojen sülfitten kaynaklandığı öne sürülmüştür. ${ }^{5}$ Literatürde demir şurupları, damlalar ve diğer preparatları alan çocukların dişlerinde meydana gelen demir renklenmeleri hakkında çok sayıda çalışma bulunmaktadır. ${ }^{6-9}$ Pani ve arkadaşlarının ${ }^{8}$ demirin ferrik formu, ferröz formu ve bu şurupların kombinasyonunun süt dişlerindeki renklenme etkisini inceledikleri çalışmalarında, 72 sonunda tüm grupların kombinasyon çözelti grubuna kıyasla oldukça yüksek ve klinik olarak görünür boyanma sergilediği belirtilmiştir. Düşük doz demir içeren Ferröz fumarat formunun diğer şuruplara göre daha az diş renklenmesine sebep olduğu gösterilmiş olsa $\mathrm{da}^{10}$, bu düşük doz formüllerin anemiyi önlemek için yeterli miktarda demir sağlamadığı endişesi ile genellikle demir sülfat formunda demir içeren yüksek dozda demir şurupları veya daha yakın zamanda ferrik hidroksit polimaltoz kompleksi reçete edilmektedir. ${ }^{11}$ Literatürde düşük doz ve yüksek doz demir preparatlarının süt dişleri üzerinde meydana gelen renklenmeye olan etkilerini inceleyen çalışmaların sayısı yeterli değildir.

Yüzey örtücü ajanlar, diş sert dokuları ve restorasyon arasında kompozitin polimerizasyon büzülmesine bağlı oluşabilecek boşlukları doldurmak için en son geliştirilen ürünlerdir. Bu ajanların herhangi bir aşındırma ya da adeziv uygulamasına gerek kalmadan tüm yüzeyler ile mükemmel bir bağlantı sağladığı düşünülmektedir. ${ }^{12}$ Yüzey örtücü ajanlar sabit ortodontik tedavi gören hastalarda mine dekalsifikasyonlarını önlemek için ortodonti pratiğinde yaygın olarak kullanılmaktadır. Özellikle ağız hijyeni yetersiz olan, plak ve renklenme olasılığı daha yüksek olan hastalar için endikedir. ${ }^{13}$ Literatürde ortodonti tedavisi gören hastalarda mine dekalsifikasyonlarında yüzey örtücü uygulamalarının etkisini inceleyen çalışmalar olmasına ragmen, ${ }^{13,14}$ bu ajanların süt dişlerinde meydana gelen renklenmeler üzerindeki etkisini inceleyen çalışma bulunmamaktadır.

Tüm bu bilgiler ışığında, bu çalışma süt dişlerine uygulanan yüzey örtücü ajanların +2 ve +3 değerlikli demir ilaçlarının kullanımına bağlı olarak oluşan renklenme üzerindeki etkilerini kıyaslamayı amaçlamaktadır. Bu amaçla oluşturulan boş hipotezler şu şekildedir,

1) +2 ve +3 değerlikli demir ilaçlarının süt dişlerinde meydana getirdiği renklenme farklı değildir.

2) Yüzey örtücü ajan uygulamasının dişlerde oluşabilecek renklenme üzerine herhangi bir etkisi yoktur.

\section{GEREÇ VE YÖNTEM}

Çalışmada kullanılan demir ilaçlarının detayları Tablo 1 de gösterildi. Demir şurubu olarak Ferrum Hausmann (Vifor International Inc., İsviçre) ve FerroSanol B (UCB Pharma GmbH, Almanya) kullanıldı. Yüzey örtücü olarak, düşük viskoziteli, ışıkla sertleşen rezin yüzey örtücü maddesi BisCover LV (Bisco Inc., Itasca, IL, ABD) kullanıldı.

Tablo 1. Çalışmada kullanılan demir şurupları.

\begin{tabular}{|c|c|c|c|}
\hline İlaç Adt & Etkin madde & Vardimci maddeler & Firma \\
\hline Ferrum Hausmann & $\begin{array}{l}50 \text { mg elementer } \\
\text { demir'c eşdeğer } \\
\text { Demir III Hidroksit } \\
\text { Polimaltoz kompleksi }\end{array}$ & $\begin{array}{l}\text { Seker, sorbitol, metil } \\
\text { paraben, propil } \\
\text { paraben, cream } \\
\text { esans1, sodyum } \\
\text { hidroksit }\end{array}$ & $\begin{array}{l}\text { Vifor International } \\
\text { Inc. İsviçre }\end{array}$ \\
\hline FerroSanol B & $\begin{array}{l}\text { glisin-sũlfat- } \\
\text { kompleksi ( } 20 \mathrm{mg} \\
\text { Fe+2 }{ }^{2} \text { esdeḡerdir), } 0.43 \\
\text { mg riboflavin }-5- \\
\text { sodyum fosfat, } 0.32 \\
\text { mg vitamin B1 } \\
\text { (tiamin hidroklorid), }\end{array}$ & $\begin{array}{l}\text { Askorbik asit, bir } \\
\text { kere rafine edilmiş } \\
\text { seker, glukoz } \\
\text { monohidrat, sorbitol, } \\
\text { sülfürik asit \% 95-98, } \\
\text { portakal esansi, armut } \\
\text { esansı, deiyonize su. }\end{array}$ & $\begin{array}{l}\text { UCB Pharma GmbH, } \\
\text { Alfred Nobel Strasse } \\
1040789 \text { Monheim- } \\
\text { ALMANYA }\end{array}$ \\
\hline
\end{tabular}

\section{Örneklerin hazırlanması}

Bu in-vitro deneysel çalışma için İstanbul Okan Üniversitesi Etik Kurulu'ndan onay (22.02.2020/118) alındı. Travma, ortodontik tedavi, mobilite gibi nedenlerle çekilmiş çürüğü ve restorasyonu olmayan, herhangi bir mine malformasyon ve renklenme görülmeyen 66 adet süt dişi kullanıldı. Çekim sonrası, dişleri çevreleyen yumuşak dokular uzaklaştırıldı ve çalışma başlayana kadar oda sıcaklığında distile su içerisinde bekletildi. Dişler elmas separe yardımıyla kole bölgesinden ayrıldı ve bukkal yüzleri üst kısımda kalacak şekilde akrilik bloklara gömüldü. Hazırlanan 
dişlerin bukkal yüzeyine $0,4 \mathrm{~cm} \times 0,4 \mathrm{~cm}$ boyutlarında etiket yerleştirildi ve etiketin etrafındaki tüm alan tırnak cilası ile kaplandı. Çalışma yüzeyine ise herhangi bir uygulama yapılmadı. Önceki bir çalışmadan ${ }^{8}$ elde edilen verilere dayanarak, $G *$ Power yazııım programı (sürüm 3.1.9.2; güç $0.95, a=0.05, \boldsymbol{\beta}=0.05$ ) kullanılarak grup başına minimum 11 örnek hesaplanarak dişler rastgele 6 gruba $(n=11)$ ayrildı.

Yüzey örtücü (+) grubunda bulunan dişlerin bukkal yüzeyi\% 37 fosforik asit jel (Etchant Gel, Prime Dent, Chicago, $\mathrm{IL}, \mathrm{ABD}$ ) ile 15 saniye süreyle asitlendi, ardından hava / su spreyi ile durulandı ve kurutuldu. Yüzeye mikro fırça ile ince bir tabaka BisCover LV (Bisco Inc., Itasca, IL, ABD) uygulandı. Uygulamadan sonra çözücünün buharlaşması için 15 saniye beklendi ve üreticinin talimatlarına göre 30 saniye süreyle ışıla (Elipar Free light 2, 1,200 mW/cm2, 3M ESPE, İrlanda) sertleştirildi.

\section{Renk değişiminin ölçümü}

Tüm renk ölçümleri, bir klinik spektrofotometre (Vita EasyShade Advance 4.0, Ivoclar Vivadent, Liechtenstein) kullanılarak standart bir beyaz arka plana karşı, D65 standart aydınlatmaya göre, CIEDE2000 renk sistemi ile yapıldı. Spektrofotometre, kendi kalibrasyon cihazı ile kalibre edildi ve ölçüm, Lee ve ark. ${ }^{15}$ tarafından geliştirilen protokol kullanılarak her örneğin merkezinde gerçekleştirildi. Her bir dişin ölçümü üç kez yapıldı ve ortalama değer kullanıldı.

Daha önce yapılmış bir çalışma ${ }^{16}$ referans alınarak dişler, içlerinde seyreltilmemiş $10 \mathrm{ml}$ ilaç solüsyonu olan beherlere günde 3 kere 8 saat aralıklarla 2'şer dakika süreyle batırıldı. Her daldırma döngüsünden sonra, dişler distile su ile yıkandı ve bir sonraki daldırma döngüsüne kadar Mcknight-Hanes ve Whitford ${ }^{17}$ tarafından belirlenen ve Amaechi ve ark. ${ }^{18}$ tarafından modifiye edilen yöntemle, $10 \mathrm{ml}$ suni tükürükte $37^{\circ} \mathrm{C}^{\prime}$ de muhafaza edildi. Bu işlem demir eksikliği tedavisi için önerilen 12 haftalık süreç ${ }^{3}$ boyunca tekrarlandı ve toplam 252 daldırma döngüsü uygulandı. Solüsyonlar ve yapay tükürükler her örnek için günlük değiştirildi. Kontrol grubunda distile su günlük olarak yenilendi. 12 haftalık kümülatif daldırma işleminden sonra, ikinci renk ölçümleri ilk ölçümlerle aynı yöntemle ve aynı koşullar altında gerçekleştirildi.

Renk ölçümleri CIEDE2000 ( $\triangle \mathrm{E} 00)$ sistemine göre yapıldı ve $\Delta \mathrm{E} 00$ değeri aşağıdaki formül kullanılarak hesaplandı. ${ }^{19}$

$$
\Delta E_{00}=\left[\left(\frac{\Delta L^{\prime}}{K_{L} S_{L}}\right)^{2}+\left(\frac{\Delta C^{\prime}}{K_{C} S_{C}}\right)^{2}+\left(\frac{\Delta H^{\prime}}{K_{H} S_{H}}\right)^{2}+R_{T}\left(\frac{\Delta C^{\prime}}{K_{C} S_{C}}\right)\left(\frac{\Delta H^{\prime}}{K_{H} S_{H}}\right)\right]^{1 / 2}
$$

\section{İstatistiksel analiz}

Çalışmada ölçümü yapılan tüm değişkenler için tanımlayıcı istatistikler yapılarak "Aritmetik Ortalama \pm Standart Hata" şeklinde gösterildi. Elde edilen değişkenlere ait öl- çülerin, solüsyon ve yüzey örtücü grupları arası farklılıklarının incelenmesinde iki yönlü varyans analizinden yararlanıldı. Analizde, Grup (Ferrum Hausmann, FerroSanolB, Distile Su) ve Yüzey Örtücü (+ ve -) temel etkileri ile Grup $x$ Yüzey Örtücü etkileşim terimine yer verildi. Modelde etkileşim terimi istatistiksel açıdan anlamlı bulunmadığı için temel etkiler, bonferroni düzeltmeli çoklu karşılaştırma testiyle ileri aşamada değerlendirildi. Verilerin analizi için SPSS 22 paket programından yararlanıldı. Tüm istatistiksel kararlarda $\mathrm{P}<0.05$ kriteri dikkate alındı.

\section{BULGULAR}

Tüm grupların ortalama renk değişiklikleri ( $\Delta \mathrm{E} 00)$ ve standart hataları Tablo 2 de gösterildi. Ferrum Hausmann $\left(\mathrm{Fe}^{+2}\right)$ şurup grubundaki dişler, FerroSanol B $\left(\mathrm{Fe}^{+3}\right)$ grubundaki dişlerden daha fazla renk değişimi gösterdi. $(p<0,001)$ Kontrol grubu olarak distile su içerisinde bekletilen dişlerde en az renk değişimi gözlendi. $(p<0,001)$ Her üç grup için de yüzey örtücü uygulanan dişlerde uygulanmayan dişlere göre daha fazla renk değişimi görüldü. ( $p<0,001)$ Grafik 1'de demir şurupları ve distile su için yüzey örtücü uygulanmış ve uygulanmamış gruplar arasındaki fark gösterildi. Tüm gruplar incelendiğinde, Ferrum Hausmann şurubunda yüzey örtücü uygulanmış dişlerde en fazla $\Delta \mathrm{E} 00$ değeri ve distile su grubunda yüzey örtücü uygulanmamış dişlerde en düşük $\Delta \mathrm{E} 00$ değeri bulundu.

Tablo 2. Her grup için $\triangle$ değerleri ( ortalama $\pm S D$ ).

\begin{tabular}{|c|c|c|c|c|c|c|c|}
\hline \multirow[b]{2}{*}{ Grup } & \multicolumn{2}{|c|}{ Yüzey Örtücũ + } & \multicolumn{2}{|c|}{ Yüzey Örtücü - } & \multicolumn{2}{|c|}{ P-Değeri } & \multirow[b]{2}{*}{$\begin{array}{l}\text { Grup* }{ }^{*} Y u ̈ z e y \\
\text { Ortücü }\end{array}$} \\
\hline & $n$ & $\begin{array}{l}\text { Ortalama } \pm \text { Std. } \\
\text { Hata }\end{array}$ & $n$ & $\begin{array}{l}\text { Ortalama } \pm \text { Std. } \\
\text { Hata }\end{array}$ & Grup & $\begin{array}{l}\text { Yüzey } \\
\text { Ortǚüu }\end{array}$ & \\
\hline Ferrum Hausmann & 11 & $12,42 \pm 1,41^{2, a}$ & 11 & $7,75 \pm 0,86^{28}$ & $<0,001$ & $<0,001$ & 0,084 \\
\hline FerroSanolB & 11 & $6,28 \pm 0,77^{b, a}$ & 11 & $3,02 \pm 0,51^{\mathrm{b}, \mathrm{s}}$ & & & \\
\hline Distile Su & 11 & $2,45 \pm 0,35$ cA & 11 & $1,45 \pm 0,31^{c .8}$ & & & \\
\hline \multicolumn{8}{|c|}{ a.b,c, Aynı sütundaki farkil üst simgelere sahip değerler istatistiksel farks gösterir. $(p<0,05)$} \\
\hline${ }^{A, A}$ Aynu sotirda & $k i f a r$ & kl üst simgelere sal & o değe & rer istatistiksel fark & gosterir. & $(0,05)$ & \\
\hline
\end{tabular}

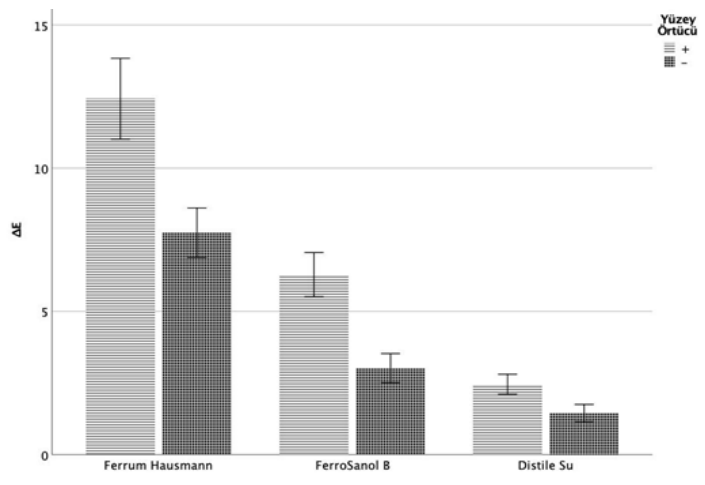

Figür 1. Tüm gruplar için $\Delta \Sigma$ değerleri

\section{TARTIŞMA}

Bu çalışmada süt dişlerinde +2 ve +3 değerlikli demir ilaçlarının kullanımına bağı olarak oluşan renklenmeler üzerinde yüzey örtücü ajanların kullanımının etkisi araştırıldı. Elde edilen sonuçlara göre ilk boş hipotezimiz '+2 ve +3 değerlikli demir ilaçlarının süt dişlerinde mey- 
dana getirdiği renklenme farklı değildir' reddedildi. Ferrik polimaltoz (Ferrum Hasumann) ve demir sülfat (FerroSanol B) Türkiye İlaç ve Tıbbi Cihaz Kurumu'ndan elde edilen verilere göre en sık reçete edilen demir şurupları arasında yer aldığı için çalışmamızda kullanıldı.

İdeal demir takviyesi dozuyla ilgili literatürde tam bir fikir birliği söz konusu değildir. Bazı çalışmalar demir damlaları ve şuruplarında doz başına 12.5 ila 50 mg demir (5 $\mathrm{ml}$ ) içermesi gerektiğini söylerken, yavaş salınan demir formüllerinin doz başına 4 ila 14.5 mg içermesi gerektiğini söyleyen çalışmalar da mevcuttur. ${ }^{11,20}$ Ferröz fumarat $\left(\mathrm{Fe}^{+3}\right)$ içeren şurupların diğer demir şuruplarından daha az renklenmeye neden olduğu bildirilmektedir, fakat bu düşük doz formülün anemi ile mücadele için yeterli olmadığı belirtilmiştir. ${ }^{21} \mathrm{Bu}$ nedenle demir sülfat $\left(\mathrm{Fe}^{+2}\right)$ gibi yüksek dozda demir içeren şuruplar daha sık reçete edilmektedir. Pani ve arkadaşları ${ }^{8}$, süt dişlerinde 72 saatin sonunda ferrik polimaltozun ferröz fumarattan anlamlı derecede daha yüksek $\Delta E^{\prime} y e$ sahip olduğunu bildirmiştir. Benzer şekilde, bizim çalışmamızda da Ferrik polimatoz $\left(\mathrm{Fe}^{+3}\right)$ içeren demir şurubu ferrik sülfat $\left(\mathrm{Fe}^{+2}\right)$ içeren demir şurubundan daha fazla renk değişimine neden oldu. Bu durum ferrik formundaki demir iyonunun, ferröz formuna göre daha hızlı kimyasal reaksiyona girmesiyle açıklanabilir. Düşük doz ferröz fumaratın yüksek dozda demir takviyeleri ile kombinasyonu ile demirin dişlerde neden olduğu renklenmenin azaltılması beklenebilir.

Zhang ve arkadaşları ${ }^{22}$ aynı beslenme tarzı olan çocuklardaki siyah lekelenmelerin demir iyonu içerip içermediğine baktıkları klinik çalışmalarında, siyah leke içeren dental plaktaki demir içeriğinin, lekelenme olmayan dental plaktaki demir içeriğinden önemli ölçüde daha yüksek olduğunu ve dental plak içerisindeki mikrobiyomun demir bileşikleri üreterek siyah lekelenmelere sebep olduğunu bildirmiştir. Demir iyonunun sebep olduğu lekelenmeleri azaltmak için, demir şuruplarını tüketmeden önce diş fırçalamak oldukça etkili bir yöntemdir. Dişlerde meydana gelen lekelenme, ilaçlarla dişlerin temas süresiyle direkt ilişkilidir. Dolayısıyla şurup ve damla şeklindeki demir preparatları daha fazla renklenmeye neden olabilmektedir. Demir şuruplarını su, meyve suyu gibi sıvılarla karıştırarak tüketmek ve pipet kullanarak içmek veya dilin arka kısımlarına damlatmak renk değişikliğini azaltabilir. ${ }^{23}$ DEA tedavisi sürecindeki çocuk hastalara yukarıda anlatılan uygulamalar hakkında bilgilendirme yapılması ile demir şuruplarının neden olduğu renklenmelerin azalması beklenebilir.

Çalışmamızın sonuçlarına göre "yüzey örtücü ajan uygulamasının dişlerde oluşabilecek renklenme üzerine herhangi bir etkisi yoktur" boş hipotezimiz de reddedildi. Yüzey örtücü ajanlar, pit ve fissürlerin üzerini örterek dişi asit ve dental plağın zararlı etkilerine karşı korumayı amaçlamaktadır. Fissür örtücülerle ilgili klinik sonuçların iyi olmasına dayanarak, bu önleyici ajanların pürüzsüz mine yüzeylerine uygulanması konsepti geliştirilmiştir. ${ }^{24}$ Özellikle sabit ortodontik tedavi gören ve ağız hijyeni yetersiz hastalarda mine dekalsifikasyonlarını ve renklenmeleri önlemek için ortodonti pratiğinde yaygın olarak kullanılmaktadır. Yüzey örtücü ajanlar, braketlerin takılmasından önce ya da sonra dişlerin labial yüzeylerine uygulanmakta ve mineyi asit saldırısına karşı fiziksel bir bariyer oluşturarak korumaktadır. ${ }^{25}$ Ancak bu yüzey örtücü ajanların yiyecek ve içecek tüketimiyle dişlerde renklenmeye neden olduğu bildirilmiştir. ${ }^{24}$ Cocodel ve ark ${ }^{14}$ yaptıkları çalışmalarında mine yüzeylerinin özellikle kompozit ve cam iyonomer esaslı yüzey örtücüler kullanılması durumunda daha fazla renklenme gösterdiğini rapor etmiştir. Benzer şekilde, bizim çalışmamızda da yüzey örtücü ajan uygulanmış tüm diş yüzeylerinde uygulanmamış diş yüzeylerine göre daha fazla renk değişimi gözlendi. Öte yandan bizim çalışmamızın aksine bazı çalışmalar, yüzey örtücü ajanların kompozit disk örneklerinin renk stabilitesini olumlu yönde etkilediğini göstermiştir. ${ }^{26,27}$ Catelan ve arkadaşları $^{28}$ yüzey örtücü uygulanmış kompozit örneklerde ultraviyole (UV) ile hızlandırılmış yaşlandırma sonrasında daha düşük renk değişimi gösterdiğini, ancak tüm gruplar için renk değişikliğinin klinik olarak kabul edilebilir olduğunu bildirmiştir. Kompozit materyallere yüzey örtücü ajan uygulanması, mevcut yüzey düzensizliklerini azaltarak daha pürüzsüz bir yüzey sağlayıp kompozit materyalin renklenme direncini artırabilir. Ancak bizim çalışmamızda çekilmiş dişlerin kullanılması sebebiyle sonuçları kıyaslamak mümkün değildir.

Diş renginin algılanması; aydınlatma koşulları, translüsensi, opasite, ışık saçılması ve insan gözü gibi birçok faktörden etkilenebilir. Görsel değerlendirme yoluyla minimum renk değişikliğinin nicel değerlendirmesi mümkün değildir. Öte yandan bu tür ölçümler için standartlaştırılmış cihazlar kullanılabilmektedir. Elektronik optiklerdeki teknolojik gelişmeler, renk seçimi için kullanılan elektronik teknikleri günlük kullanım için daha uygun hale getirmektedir. ${ }^{29} \mathrm{Bu}$ çalışmada renk değerlendirmesindeki olası öznel hataları en aza indirmek için renk ölçümlerinde bir spektrofotometre (VITA Easyshade sistemi (Vita Zahnfabrik, BadSäckingen, Almanya)) kullanıldı.

Diş hekimliğinde renk analizlerinde en sık kullanılan CIE $L \star a * b$ renk değişim sistemi Commission Internationale de l'Eclairage tarafından tanımlanmıştır. Ancak 2001'den beri Uluslararası Aydınlatma Komisyonu (CIE) tarafından yeni bir renk sistemi olan CIEDE2000 ( $\triangle E$ E00) sistemi önerilmektedir. 2013 yılında bu sistem, renk farklılıklarını tespit etmek için standart olarak kabul edilmiştir. ${ }^{30}$ Bu sistemde, kullanılan parametrelerin sayısı artırılmış ve hesaplamalar CIE $L * a * b$ sistemine göre daha karmaşık hale gelmiştir. Renk algısı, farklı parlaklık seviyelerine sahip arka plan- 
lara göre değişiklik gösterdiğinden, renk algısındaki bu değişiklik ölçeğe dahil edilmiştir. CIEDE2000 renk sistemi CIE $L * a * b$ sisteminden kaynaklı hataları düzelterek ölçülen ve algılanan renk değişimi miktarları arasında daha iyi bir korelasyon sağlamaktadır. Böylece CIE $L * a * b$ sistemine göre insan gözünün renk farkları ile ilgili algılanabilirlik ve kabul edilebilirlik eşik değerlerini daha iyi göstermektedir. ${ }^{31}$ CIEDE2000 renk sisteminin avantajları göz önünde bulundurularak bu çalışmada CIEDE2000 renk sistemi tercih edildi.

Çalışmamızın, yiyecek-içecek tüketimi ve oral hijyen alışkanlıkları gibi renklenme değişimini etkileyebilecek faktörleri içermemesi ve dolayısıyla ağız ortamını birebir taklit edememesi gibi bir takım kısıtlamaları bulunmaktadır. Sonuçlarımızın in vitro koşullar için geçerli olduğunu düşünürsek, yapılacak in vivo çalışmalar ile daha kapsamlı bilgiler ortaya çıkacağına inanıyoruz.

\section{SONUÇLAR}

$\mathrm{Bu}$ çalışmanın sonuçları in-vitro test edildiğinde demirin süt dişleri üzerinde boyama potansiyeline sahip olduğunu göstermektedir. Demir şurubunun içeriğindeki demirin formu dişlerde meydana gelen renk değişimini etkilemektedir. $\mathrm{Fe}^{+2}$ içeren şurupların $\mathrm{Fe}^{+3}$ içeren şuruplara göre daha fazla renklenmeye neden olduğu düşünülerek, çocuk hastalarda kullanılan demir şuruplarının içeriğinin geliştirilmesi üzerine bir halk sağlığı politikası oluşturulabilir. Yüzey örtücü uygulamalarının restoratif materyallerde olumlu etkileri olduğu bilinmesine rağmen, mine yüzeylerinde renk değişimine neden olabildiği gözlenmektedir. Kontrol grubu da dahil olmak üzere tüm gruplarda yüzey örtücü uygulanmış dişlerde yüzey örtücü uygulanmamış dişlere göre daha yüksek renk değişimi gözlenmesi yüzey örtücü uygulamalarının süt dişlerinde renklenmeye neden olduğu hipotezini desteklemektedir. Demir şuruplarının ve yüzey örtücü ajanlarının süt dişleri üzerindeki etkilerini değerlendirmek için daha kapsamlı in-vitro çalışmaların gerçekleştirilmesi ve bu sonuçların klinik çalışmalarla desteklenmesi gerekmektedir.

\section{KAYNAKLAR}

1. Sanlı C, Kocak U, Albayrak M, Aliefendioglu D. Kırıkkale Üniversitesi Tıp Fakültesi'ne başvuran çocuklarda demir eksikliği anemisi sıklığı ve beslenme durumu ile ilişkisi. Çocuk Derg 2005;5:184-189.

2. Kaya Z, Gursel T, Bozkurt R, Koçak U, Aral Y. Çocuklarda anemi sıklığı ve enfeksiyon anemi ilişkisi. Ege Tıp Derg 2007;46:37-40.

3. Arabaci F, Kaya A, Gultekin A, İcagasıoglu F, Mutlu E. Çocuklarda Demir Eksikliği Anemisinin Tedavisinde +2 ve + 3 Değerlikli Demir içeren ve + 2 Değerlikli Demirle Birlikte Çinko İçeren Preperatların Etkinliklerinin Karşılaştırıması. Turkiye Klinikleri J Pediatr 2010;19:210-215.
4. Kumar A, Kumar V, Singh J, Hooda A, Dutta S. Drug-induced discoloration of teeth: an updated review. Clin Pediatr 2012;51:181-185.

5. Addy M, Moran J. Mechanisms of stain formation on teeth, in particular associated with metal ions and antiseptics. Adv Dent Res 1995;9:450-456.

6. Adcock KG, Hogan SM. Extrinsic iron staining in infant teeth from iron-fortified formula and rice cereal. The journal of pediatric pharmacology and therapeutics : JPPT : the official journal of PPAG. 2008;13:162-165.

7. Eshghi $A$, Kowsari-Isfahan R, Rezaiefar $M$, Razavi $M$, Zeighami S. Effect of iron containing supplements on rats' dental caries progression. J Dent (Tehran). 2012;9:14-19. 8. Pani SC, Alenazi FM, Alotain AM, Alanazi HD, Alasmari AS. Extrinsic tooth staining potential of high dose and sustained release iron syrups on primary teeth. BMC oral health. 2015; 15:90.

9. Talebi M, Parisay I, Mokhtari N. The parents' knowledge and behavior towards the effects of using iron supplements on tooth staining and dental caries in Mashhad, Iran Dental Res J 2012;9:715-718.

10. 1Christofides A, Asante KP, Schauer C, Sharieff W, Owusu-Agyei S, Zlotkin S. Multi-micronutrient Sprinkles including a low dose of iron provided as microencapsulated ferrous fumarate improves haematologic indices in anaemic children: a randomized clinical trial. Maternal \& child nutrition 2006;2:169-180.

11. Rao R, Georgieff MK. Iron therapy for preterm infants. Clinics in Perinatol 2009;36:27-42.

12. Magni E, Zhang L, Hickel R, Bossu M, Polimeni A, Ferrari $\mathrm{M}$. SEM and microleakage evaluation of the marginal integrity of two types of class $V$ restorations with or without the use of a light-curable coating material and of polishing. J Dent 2008;36:885-891.

13. Sen $S$, Erber R, Kunzmann $K$, et al. Assessing abrasion of orthodontic surface sealants using a modified ophthalmic optical coherence tomography device. Clin Oral Invest 2018;22:3143-3157.

14. Corcodel N, Hassel AJ, Sen S, et al. Effects of staining and polishing on different types of enamel surface sealants. J Est Rest Dent 2018;30:580-586.

15. Lee BS, Huang SH, Chiang YC, Chien YS, Mou CY, Lin CP. Development of in vitro tooth staining model and usage of catalysts to elevate the effectiveness of tooth bleaching. Dent Material 2008;24:57-66.

16. Tuzuner T, Turgut S, Baygin O, Yilmaz N, Tuna EB, Ozen B. Effects of Different Pediatric Drugs on the Color Stability of Various Restorative Materials Applicable in Pediatric Dentistry. BioMed Res Int 2017;2017:9684193.

x McKnight-Hanes C, Whitford GM. Fluoride release from three glass ionomer materials and the effects of varnishing with or without finishing. Caries Res 1992;26:345350. 
18. Amaechi BT, Higham SM, Edgar WM. Factors influencing the development of dental erosion in vitro: enamel type, temperature and exposure time. J Oral Rehab 1999;26:624-630.

19. 1Alberton Da Silva V, Alberton Da Silva S, Pecho OE, Bacchi A. Influence of composite type and light irradiance on color stability after immersion in different beverages. J Esthet Rest Dent 2018;30:390-396.

20. Quinn EA. Too much of a good thing: evolutionary perspectives on infant formula fortification in the United States and its effects on infant health. Am J Human Biol 2014;26:10-17.

21. Griffin IJ, Cooke RJ, Reid MM, McCormick KP, Smith JS. Iron nutritional status in preterm infants fed formulas fortified with iron. Archives of disease in childhood. Fetal and neonatal edition 1999;81:F45-49.

22. Zhang F, Li Y, Xun Z, Zhang Q, Liu H, Chen F. A preliminary study on the relationship between iron and black extrinsic tooth stain in children. Letters in App Microb 2017;64:424-429.

23. Miguel JC, Bowen WH, Pearson SK. Influence of iron alone or with fluoride on caries development in desalivated and intact rats. Caries Res 1997;31:244-248.

24. Korbmacher-Steiner HM, Schilling AF, Huck LG, KahlNieke B, Amling M. Laboratory evaluation of toothbrush/ toothpaste abrasion resistance after smooth enamel surface sealing. Clin Oral Invest 2013;17:765-774.

25. Yap J, Walsh LJ, Naser-Ud Din S, Ngo H, Manton DJ. Evaluation of a novel approach in the prevention of white spot lesions around orthodontic brackets. Aust Dent $\mathrm{J}$ 2014;59:70-80.

26. Miotti LL, Nicoloso GF, Durand LB, Susin AH, Rocha RO. Color stability of a resin composite: Effect of the immersion method and surface treatments. Indian J Dent Res 2016;27:195-199.

27. Pedroso LB, Barreto LF, Miotti LL, Nicoloso GF, Durand $L B$. Effect of a surface sealant on the color stability of composite resins after immersion in staining solution. General Dent 2016;64:e22-25.

28. Catelan A, Suzuki T, Becker F, Briso A, Dos Santos P. Influence of surface sealing on color stability and roughness of composite submitted to ultraviolet-accelerated aging. J Invest Clin Dent 2017;8.

29. Guler AU, Guler E, Yucel AC, Ertas E. Effects of polishing procedures on color stability of composite resins. J App Oral Sci 2009;17:108-112.

30. Gomez-Polo C, Muñoz M, Luengo $M$, Vicente $P$, Galindo P, Casado A. Comparison of the CIELab and CIEDE 2000 color difference formulas. The J Prosth Dent 2016;115:65-70.

31. Pecho OE, Ghinea R, Alessandretti R, Perez MM, Della Bona $A$. Visual and instrumental shade matching using CIELAB and CIEDE2000 color difference formulas. Den- tal Material 2016;32:82-92. 